\title{
Aproximación al estudio arqueopetrológico de la industria lítica procedente del abrigo de La Roureda (Vilafranca, Els Ports, Castelló, País Valencià)
}

\author{
Mar Rey-Solé, Dídac Roman, Javier Mangado \\ SERP. Departamento de Prehistoria, Historia Antigua y Arqueología. Universidad de Barcelona. C/ Montalegre \\ 6. 08001. Barcelona, Cataluña. \\ Email: Rey-Solé: mreysole@ub.edu; Roman: didacroman@ub.edu; Mangado: mangado@ub.edu
}

\section{Resumen:}

El abrigo de la Roureda es un yacimiento epimagdaleniense situado en la comarca de Els Ports, al este de la Península Ibérica.

El yacimiento fue descubierto en la década de los años 70, aunque no fue hasta el año 2007 cuando la excavación de un sondeo de $2 \mathrm{~m}^{2}$ permitió definir una ocupación del Epimagdaleniense antiguo, datado en el 11350 \pm 50 BP (13373-13122 cal. BP).

Una de las principales características del yacimiento es la abundante industria lítica, toda ella sobre sílex. La colección de 4.639 restos ha sido objeto de diversos estudios (tipología, tecnología), siendo este trabajo la primera aproximación arqueopetrológica.

El estudio se divide en dos partes; en primer lugar se ha procedido al análisis macroscópico, conjugando análisis petrológicos y micropaleontológicos de la totalidad de material retocado recuperado en el abrigo (286), de los restos de talla (2.753) - la totalidad de 4639 restos incluía también esquirlas, por lo que el análisis se ha centrado solo en los soportes (2459) incluyendo sólo las esquirlas más grandes de $1 \mathrm{~cm}$ (294), rebajando el número a un total de 2753 restos analizados- y de los núcleos (20), procedentes de los cuadros C3 y E3. En segundo lugar se han llevado a cabo análisis microscópicos de las variedades de sílex identificadas macroscópicamente así como prospecciones geológicas en la región, lo que nos ha permitido documentar diversos afloramientos de material sedimentario silíceo.

El análisis comparativo entre la materia prima de los afloramientos y la del yacimiento nos ha permitido aproximarnos a las posibles fuentes de abastecimiento de los grupos epimagdalenienses que ocuparon el abrigo. Se trata de un primer análisis en el marco de un proyecto más amplio que pretende analizar otros yacimientos del Paleolítico superior al Mesolítico y conocer las fuentes de abastecimiento de materias primas líticas en la Prehistoria de la zona norte del País Valenciano, lo que le confiere una gran relevancia no únicamente para conocer la economía de las materias primas del abrigo de la Roureda, sino también para empezar a conocer las posibilidades del abastecimiento del sílex de este amplio territorio.

Palabras clave: sílex; materias primas; arqueopetrología; País Valenciano; patrones de movilidad prehistóricos

Published by the School of History, Classics and Archaeology, University of Edinburgh ISSN: 2055-0472. URL: http://journals.ed.ac.uk/lithicstudies/

This work is licensed under a Creative Commons Attribution 2.5 UK: Scotland License. 


\section{Introducción}

La Arqueopetrología estudia las materias primas arqueológicas tanto desde un punto de vista cultural como desde su materialidad, como elemento geológico. Esta perspectiva de estudio debe considerarse como fundamental en la praxis arqueológica actual porque proporciona datos geográficos y por lo tanto territoriales de los materiales estudiados (Mangado 2004: 11; Rey 2011: 36).

La caracterización petrográfica (macroscópica y microscópica) de los útiles líticos es un estudio que contribuye a analizar la conducta de los grupos humanos desde tres perspectivas diferentes (Parcerisas 2006):

- a nivel espacial, nos facilitará el establecimiento de patrones de movilidad e intercambio;

- a nivel tecnológico podremos identificar la adecuación entre los procesos técnicos de manufactura y la materia prima seleccionada; y

- a nivel de organización social será posible averiguar el desarrollo de estrategias en la adquisición y selección de recursos líticos.

\section{Objetivos}

La excavación del abrigo de la Roureda ha permitido la recuperación de un elevado número de restos de industria lítica. Este estudio tiene como objetivo primero establecer las características petrográficas y el origen geológico y geográfico de las materias primas utilizadas y, por lo tanto, intentar deducir qué territorio explotaron dichas comunidades y qué estrategias de abastecimiento llevaron a cabo.

Las comunidades prehistóricas que habitaron el abrigo explotaban ciertos recursos que actualmente son una realidad tangible arqueológicamente. Conocer la relación de dichas comunidades con los espacios geográficos es primordial en Prehistoria, pues en ellos se arraigan fenómenos económicos y culturales de orden material y simbólico. Así pues, los comportamientos de adquisición de dichos recursos presiden de manera directa y activa la percepción de los paisajes y su integración en el cotidiano de los pobladores de la época y su grado de movilidad (Mangado 2005).

Este artículo abordará el estudio de toda la industria lítica hasta ahora recuperada en el yacimiento, analizando elementos de toda la cadena operativa, tanto núcleos, como restos de talla y útiles retocados. Aunque en su totalidad se trate de sílex, se aprecia que éste presenta distintas variedades. En este trabajo analizamos las diferentes variedades documentadas para luego contextualizarlas geográfica y geológicamente. Otro de los objetivos de este estudio es poder averiguar si dichas variedades de sílex tenían o no un uso diferencial.

\section{El Abrigo de la Roureda}

El abrigo de la Roureda se encuentra ubicado en el margen derecho del barranco de la Font d'Horta, en el término municipal de Vilafranca, Els Ports, Castellón (Figura 1). Fue descubierto por el Dr. en Geología Ferran Arasa a finales de los años 70 del siglo XX en una de sus prospecciones por el término de Vilafranca (Arasa, 1977). A raíz del descubrimiento, el Dr. Dídac Roman realizó una revisión de los materiales del mismo, previamente depositados en el Museo de Bellas Artes de Castelló, cuyos resultados positivos motivaron el planteamiento de la futura excavación del lugar.

Se trata de una pequeña cavidad situada a 1.150 m s.n.m. y con unas dimensiones de $6 \mathrm{~m}$ de longitud por $2 \mathrm{~m}$ de profundidad. La primera campaña de excavación se realizó en el año 2007 y consistió en un sondeo de 2 m² (cuadros C3 y E3) (Figura 2) evidenciándose una secuencia arqueológica caracterizada por la existencia de un único nivel de ocupación (Nivel 
II) que aportó una datación radiocarbónica sobre carbón de $11350 \pm 70$ BP (13.360-13.090 cal. BP; Beta-244009) (Román 2010: 11).

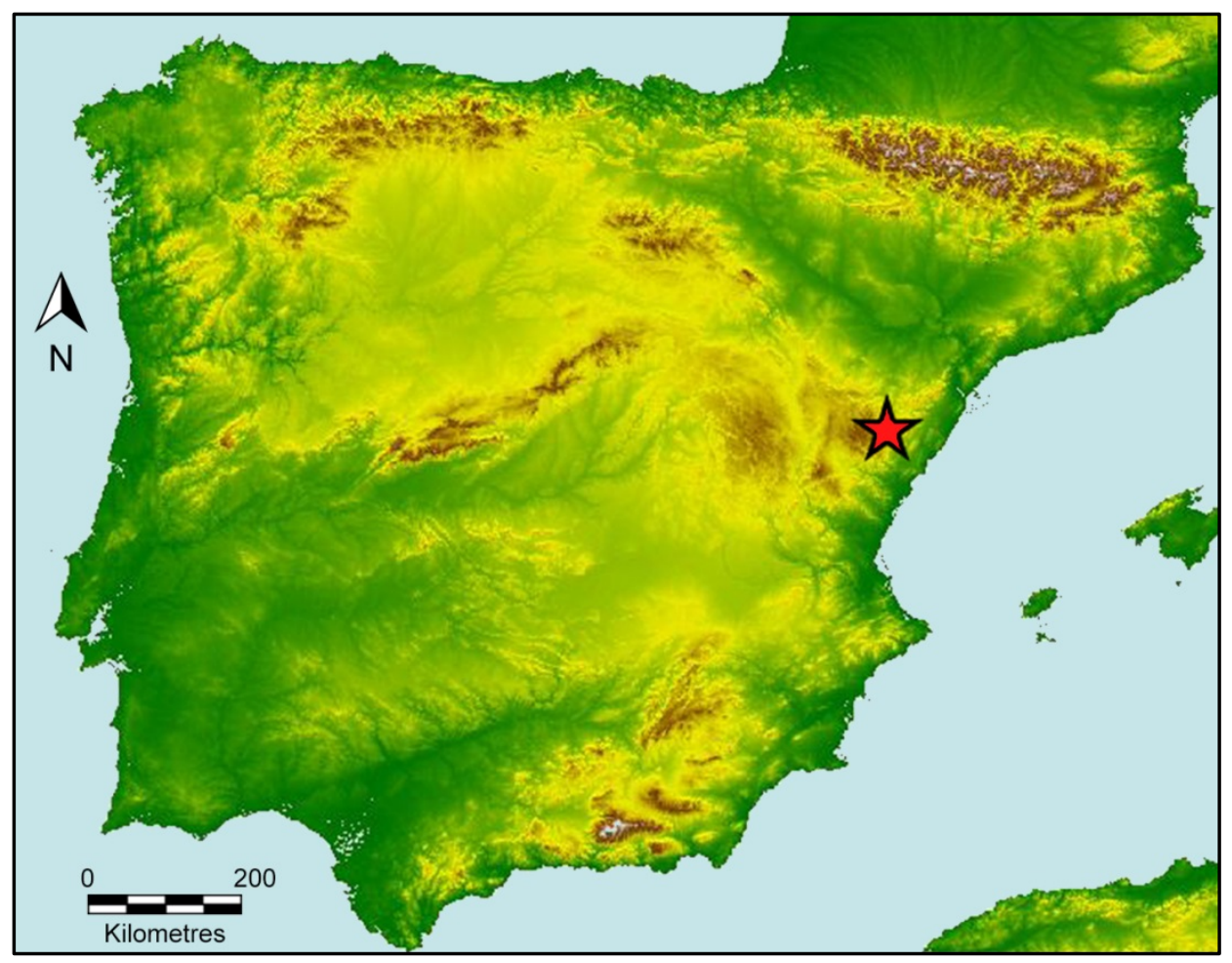

Figura 1. Localización del abrigo de La Roureda en el contexto de la Península Ibérica.

Figure 1. Location of La Roureda's Rockshelter within the context of the Iberian Peninsula.

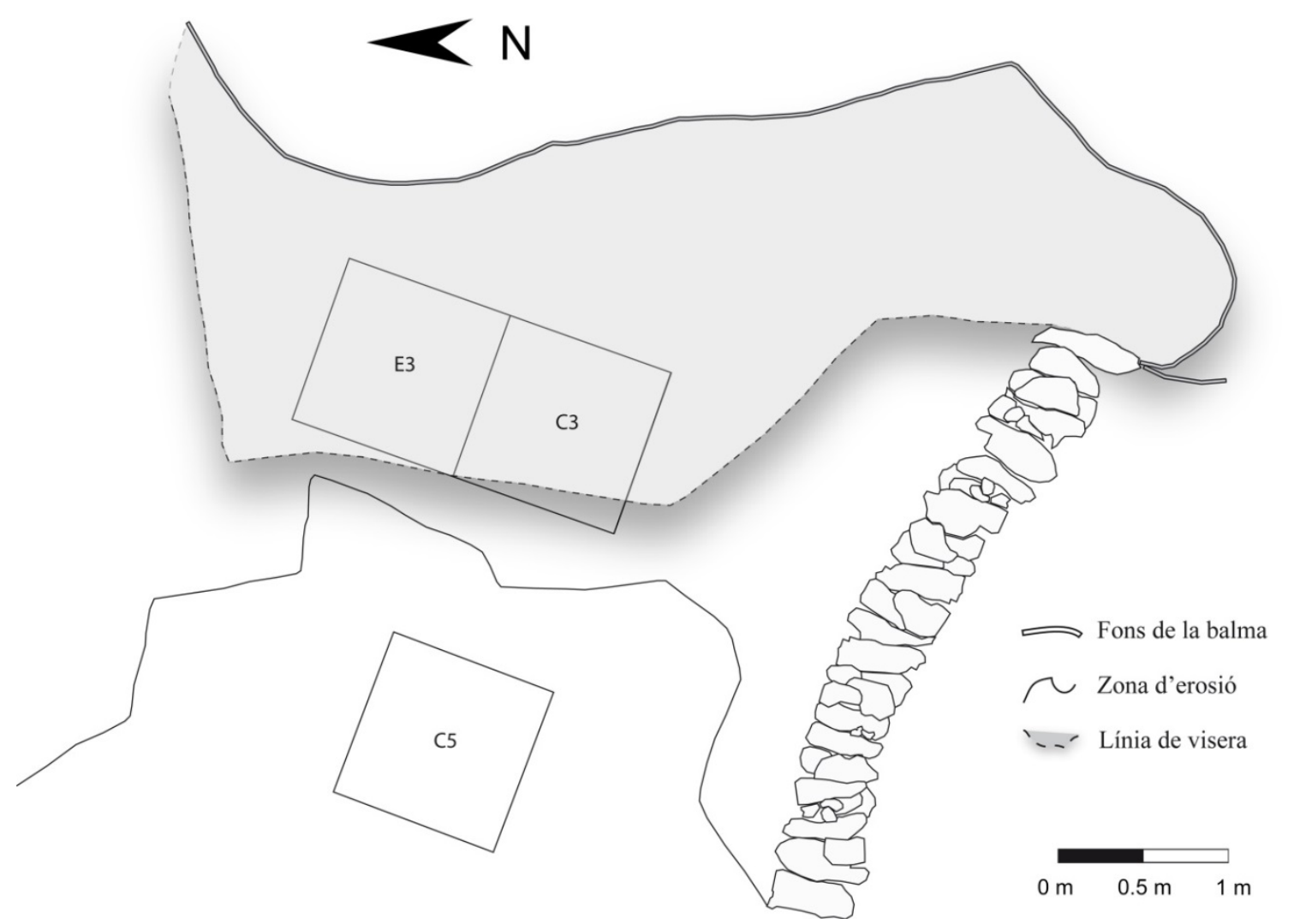

Figura 2. Planta del abrigo de La Roureda (Roman 2011b: 22).

Figure 2. Site plan of La Roureda’s Rockshelter (Roman 2011b: 22). 
La industria lítica recuperada fue abundante, con un total de 4.639 restos, de los cuales 286 pertenecen a material retocado (Figura 3). Junto con estas piezas se recuperaron un pequeño lote de restos faunísticos, destacando diversos fragmentos de malacofauna (Pecten jacobeus) (Román 2011a: 193) y dos gasterópodos perforados (Theodoxus fluviatilis). El estudio de todos estos restos ha permitido adscribir el yacimiento al Epimagdaleniense antiguo.
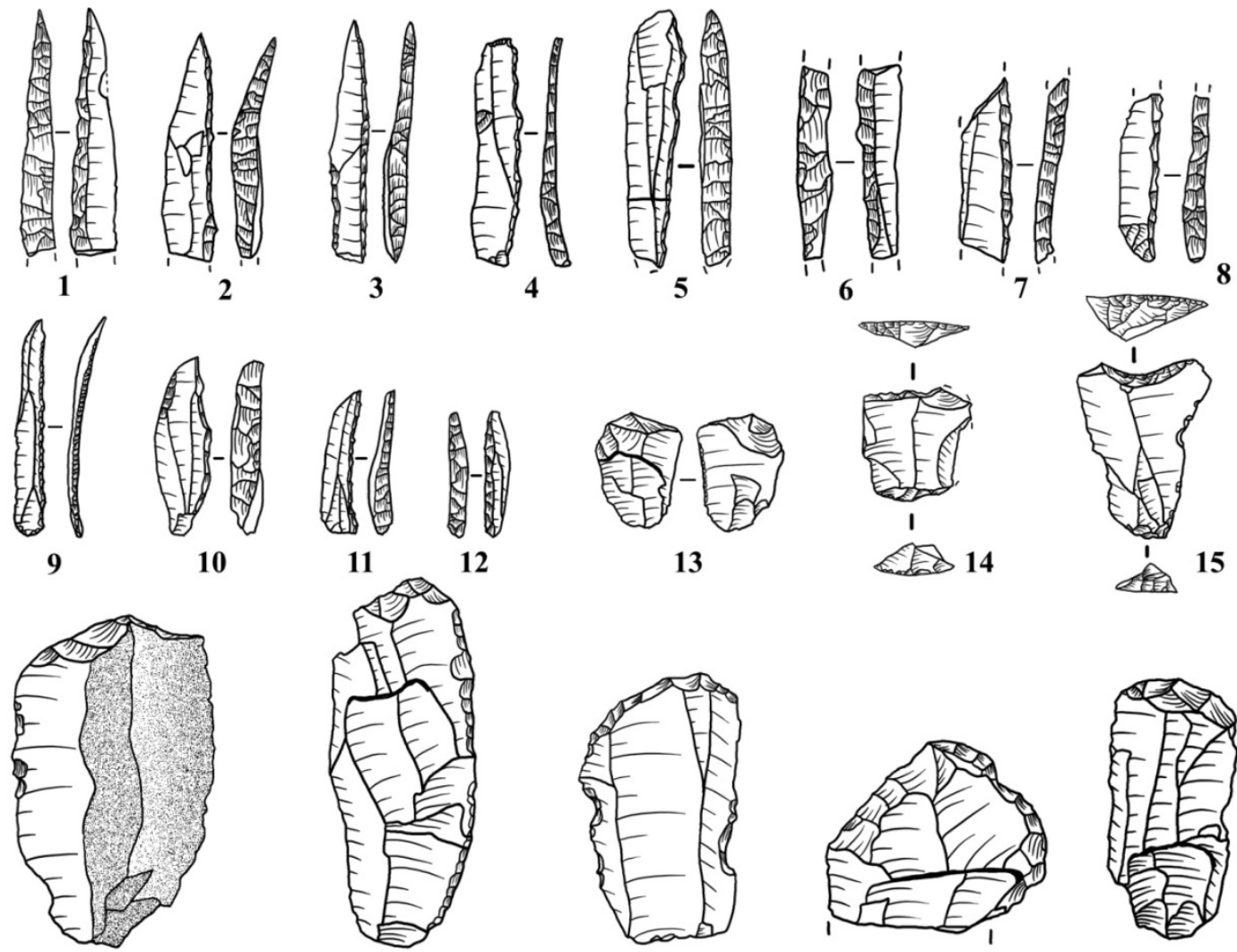

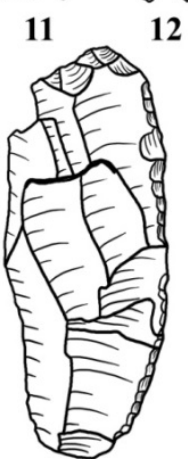

17

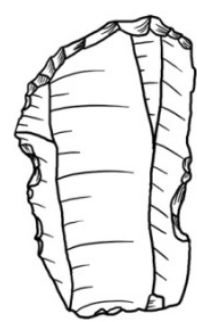

18
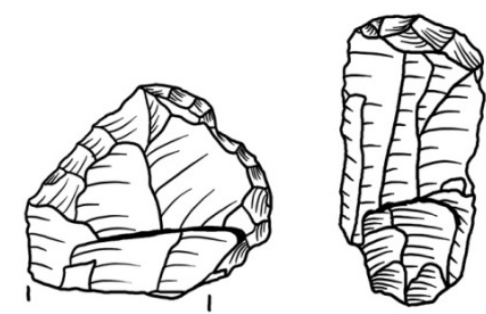

19

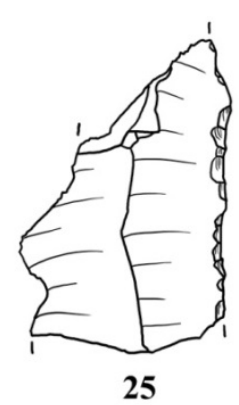

20

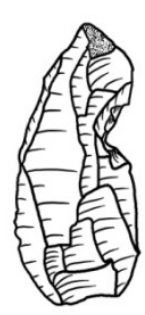

21

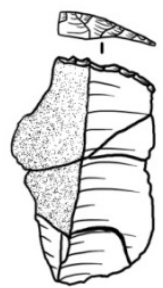

26

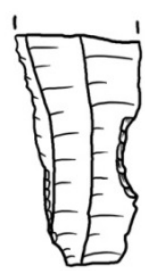

22

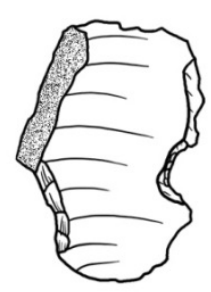

23

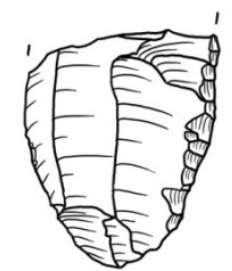

24

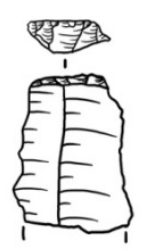

28

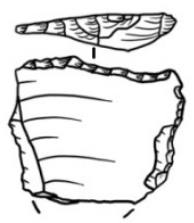

29

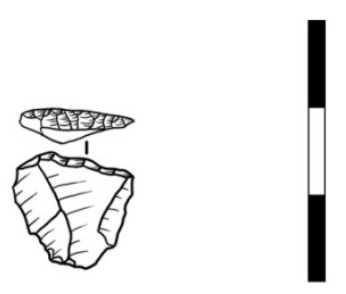

30

Figura 3. Industria lítica del abrigo de La Roureda: 1-12. utillaje microlaminar; 13. pieza astillada; 14-15. útiles compuestos; 16-20. raspadores; 21-23. muescas y denticulados; 24-25. piezas con retoques en los bordes; 26-30. truncaduras. Escala: cada partición equivale a $1 \mathrm{~cm}$.

Figure 3. Lithics from La Roureda's Rockshelter: 1-12. microlaminar tools; 13. écaillée tool; 14-15. composite tools; 16-20. end scrapers; 21-23. notches and denticulates; 24-25. retouched tools; 26-30. truncatures. Scale bars are in $1 \mathrm{~cm}$ segments. 


\section{Materiales y metodos}

El conjunto de restos analizado para este trabajo consta de 3.059 vestigios, entre los que se incluyen, además de todos los restos líticos mayores de $1 \mathrm{~cm}$, las piezas retocadas (286) y la totalidad de los 20 núcleos recuperados. El análisis macroscópico textural se ha llevado a cabo con una lupa estereoscópica Olympus KL 1500 LCD con fuente de luz fría cenital -y una fuente de iluminación complementaria en función de las muestras, de luz fría transmitida Olympus TH4-200- a diversos aumentos: de 0,67x a 4,5x. Las imágenes se han tomado con una cámara fotográfica Olympus SC20.

El análisis microscópico se ha realizado sobre un total de 19 láminas delgadas sobre muestras arqueológicas: cinco muestras del Tipo A-I y cinco del A-II; cinco del Tipo B, una del Tipo C y tres del Tipo D. El microscopio óptico utilizado ha sido un Olympus modelo BX41, con cámara acoplada Olympus SC-30. Las muestras han sido observadas entre 4 y 40 aumentos (teniendo en cuenta los 10 aumentos de los oculares).

\section{Características texturales y variedades de sílex}

\subsection{Análisis macroscópico}

El análisis macroscópico textural, incluyendo la determinación de la micropaleontología hallada (dónde autores como Mauger 1984 explican la importancia de ésta) han hecho posible la discriminación de diferentes variedades de sílex (Tabla 1 y Figura 4).

Tabla 1. Características de definición de los diferentes tipos.

Table 1. Characteristics of the chert types.

\begin{tabular}{llllllll}
\hline & & & & & & \\
\end{tabular}

Tipo A: Consta de un total de 153 piezas retocadas (53,50\%) y 1.937 de restos de talla (70,35\%). Presenta un grano muy fino y es extremamente homogéneo (99\% libre de clastos, y si los contiene corresponden a restos de algas carofíceas, gasterópodos o ambos, se trata pues de una textura heredada tipo Mudstone. Opaco, de brillo céreo y córtex calizo-margoso. Su origen es salobre o lacustre y según su aptitud a la talla se clasificaría como "de buena a muy 
buena”. Este tipo presenta dos variedades cromáticas, la variedad I, (en adelante A-I) de color 10 YR (3/1) Very dark grey (86 retocados, 1.039 restos de talla y 10 núcleos) y la variedad II, (en adelante A-II) de color 10 YR (5/3) Brown, translúcido (67 retocados, 898 restos de talla y un núcleo). Autores como Masson (1981) o Luedtke (1992) advierten de la gran variabilidad colorimétrica del sílex, descartando dicho criterio como exclusivo para la discriminación de sílex.


Figura 4. 1. muestra c3c4-18, fragmento de lasca con retoques en un borde; clasificado como Tipo A-I. 2. muestra c3c3-19, fragmento de pieza con un dorso, clasificada como Tipo A-II. 3. muestra c3c4-3, lasca con muescas, clasificada como Tipo B. 4. muestra c3c6-36, fragmento de lámina con muescas, clasificada como Tipo C. 5. muestra no retocada núm. 5, clasificada como Tipo D. 6 muestra c3c4-5, fragmento de lámina truncada recta, clasificada como patinada.

Figure 4. 1. sample c3c4-18, side retouched flake fragment; classified as A-I Type. 2. sample c3c3-19, backed blade fragment, classified as A-II. 3. sample c3c4-3, notched flake, classified as B Type. 4. sample c3c6-36, notched bladelet fragment, classified as C Type. 5. sample n. 5, non retouched, classified as D Type. 6. sample c3c4-5, fragment of truncated bladelet, classified as patinated. 
Tipo B: Éste es de grano fino a grueso; los clastos, mal seleccionados, son tanto de origen litológico como biológico y se hallan en un porcentaje superior al 40\%: pseudomorfos romboidales de Calcita/Dolomita, restos de tallo y oogonios de algas carofíceas y gasterópodos enteros o fracturados, confiriendo una gran heterogeneidad a las muestras. Su textura heredada correspondería a una transición de Wackestone a Packstone. Es un material translúcido, de brillo vítreo y de color 7,5 YR (4/1) Dark grey. Por sus características, micropaleontológicas y mineralogía, su origen sería salobre o lacustre. La calidad para la talla sería “mediocre a buena”. El tipo B agrupa 55 retocados, 262 restos de talla y cinco núcleos.

Tipo C: Presenta un grano de tamaño fino a medio, es azoico y exento de clastos, clasificándose de textura cristalina; de color 10 YR (8/1) White y translúcido-transparente cuando se observa al trasluz. Este tipo no contiene signos suficientemente discriminatorios como para asignarle un posible origen. Su calidad para la talla "de buena a muy buena”. Integra 12 retocados y 30 restos de talla (1,09\%) No hay núcleos de este tipo.

Tipo D: Presenta un grano de tamaño fino a medio, su textura heredada se clasifica como Wackestone - Packstone, bioclástica, mate, opaca y color 2.5Y (6/2) Light Brown gray (y moteado). Representado por 44 retocados y 116 restos de talla. Su origen pudiera ser marino. Su aptitud para la talla es “mediocre”. No hay núcleos de este tipo.

Además contamos con 22 retocados, 408 restos de talla y cuatro núcleos inclasificables por su alto grado de patinación.

\subsection{Corticalidad de la industria lítica}

En relación a la corticalidad (Tablas 2, 3, 4 y Figura 5) señalaremos que:

Tipo A-I: el porcentaje de piezas retocadas con restos de córtex asciende al 18,60\% y es del 9,72\% para los restos de talla. Un total de seis núcleos conservan parte del córtex (cuyos restos oscilan entre el 10 al 50\%), la corticalidad es elevada, dato que concordaría con una configuración de los núcleos en el mismo yacimiento.

Tipo A-II: el porcentaje de piezas retocadas con restos de córtex es del 5,97\% y el 7,34\% de los restos de talla, tan sólo hemos recuperado un núcleo de este tipo que conserva parte del córtex (15\%). La corticalidad es baja, hecho que indicaría que los núcleos de este tipo llegarían ya preparados al yacimiento.

Tipo B: las piezas retocadas corticales asciende al 3,63 \% y el córtex está presente en el $4,96 \%$ de restos de talla. Dos de los cinco núcleos recuperados conservan parte del córtex (entre el 15-50\%).

El Tipo C no aparece representado en este análisis. Por lo que respecta al Tipo D sólo el $3,44 \%$ de los restos de talla conserva córtex.

Tabla 2. Clasificación de los útiles retocados en relación al tipo de sílex incluyendo el recuento de muestras con córtex.

Table 2. Classification of retouched tools in relation to their chert variety including the observation of cortex.

\begin{tabular}{llcccc}
\hline Variedad & & Núm & $\mathbf{\%}$ & Córtex & $\mathbf{\%}$ \\
\hline Tipo A & I & 86 & 30,07 & 16 & 18,60 \\
& II & 67 & 23,43 & 4 & 5,97 \\
Tipo B & & 55 & 19,23 & 2 & 3,63 \\
Tipo C & 12 & 4,20 & 0 & 0 \\
Tipo D & 44 & 15,38 & 0 & 0 \\
Patinado & 22 & 7,69 & 0 & 0 \\
\hline
\end{tabular}


Tabla 3. Clasificación de los restos de talla en relación al tipo de sílex incluyendo el recuento de muestras con córtex.

Table 3. Classification of knapping remains in relation to their chert variety including the observation of cortex.

\begin{tabular}{llcccc}
\hline Variedad & & Núm & \% & Córtex & \% \\
\hline Tipo A & I & 1.039 & 37,74 & 101 & 9,72 \\
& II & 898 & 32,61 & 66 & 7,34 \\
Tipo B & & 262 & 9,51 & 13 & 4,96 \\
Tipo C & 30 & 1,09 & 0 & 0 \\
Tipo D & 116 & 4,22 & 4 & 3,44 \\
Patinado & 408 & 14,82 & 10 & 2,45 \\
\hline
\end{tabular}

Tabla 4. Clasificación de los núcleos en relación al tipo de sílex incluyendo el recuento de muestras con córtex. Table 4. Classification of lithic cores in relation to their chert variety including the observation of cortex.

\begin{tabular}{lcccc}
\hline & & Núm & \% & Córtex \\
\hline Tipo A & I & 10 & $50 \%$ & 6 \\
& II & 1 & $5 \%$ & 1 \\
Tipo B & & 5 & $25 \%$ & 2 \\
Tipo C & 0 & & - \\
Tipo D & 0 & & - \\
Indeterminados - Patinados & 4 & $20 \%$ & 0 \\
\hline
\end{tabular}

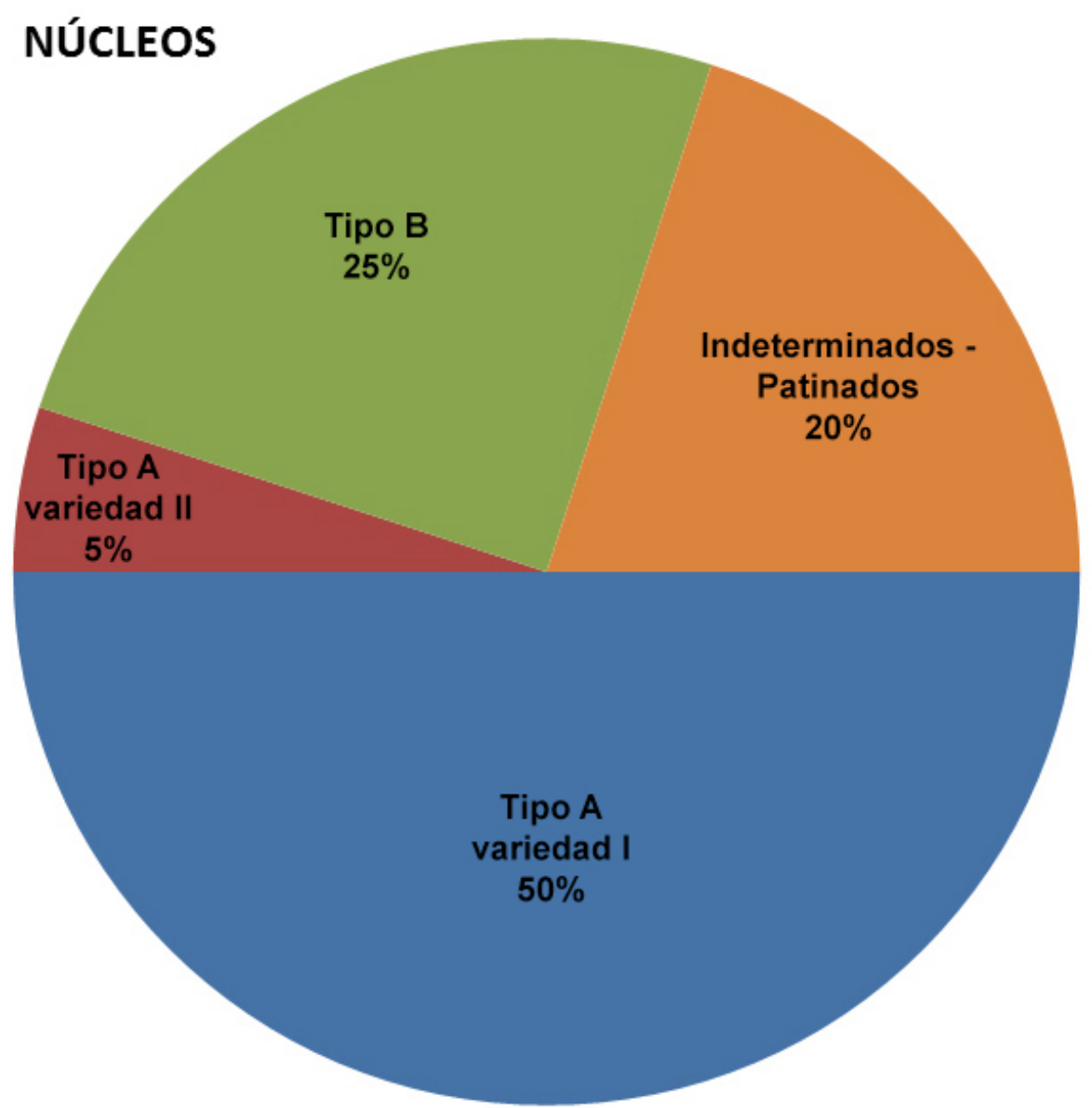

Figura 5. Diagrama de los núcleos en relación al tipo de sílex incluyendo el recuento de muestras con córtex. Figure 5. Diagram of lithic cores in relation to their chert variety including the observation of cortex. 


\subsection{Análisis Microscópico}

Tipo A: presenta una matriz micro y criptocristalina de cristales euhédricos de microcuarzo de extinción ondulante, pudiendo contener hasta un 10\% de calcedonia; su textura heredada es Mudstone por lo que el hallazgo de bioclastos es casi anecdótico: carófitos, ostrácodos y restos de foraminíferos aislados son muy ocasionales, no llegando a superar el 5\% sobre el total de la muestra. Se ha comprobado que A-I y A-II coinciden texturalmente, hecho que confirmaría su correspondencia al mismo tipo. El análisis conjunto de la textura y la micropaleontología confirma un ambiente de formación de transición, de aguas dulces a saladas u origen salobre o lacustre.

Tipo B: también presenta una matriz microcristalina de cristales euhédricos de microcuarzo de extinción ondulante; se diferencia del Tipo A por la inclusión de un mayor número de bioclastos, pudiéndose hablar claramente de una textura heredada Packstone bioclástico ( $>30 \%$ clastos) formado básicamente por gasterópodos, carófitos y algunos foraminíferos. Al igual que el caso anterior, su ambiente de formación sería salobre o lacustre.

Texturalmente, ambos tipos son prácticamente iguales a excepción de la concentración y porcentaje de bioclastos, mucho más abundantes en el Tipo B (Packstone) que en el Tipo A (Mudstone). Pudiera ser que ambos tipos de sílex procedan de una misma formación, pero de diferentes biofacies, es decir, facies que contengan distintas concentraciones de restos biológicos, lo cual explicaría el contraste de texturas hallada. Este cambio textural pudiera tener su reflejo arqueológico, ya que podría repercutir en una distinta calidad para la talla siendo el Tipo A de calidad muy superior y, por lo tanto, los útiles manufacturados de uno u otro tipo estarían condicionados por este hecho.

Tipo C: en este caso la matriz criptocristalina de cristales euhédricos de microcuarzo de extinción ondulante no presenta suficientes criterios ni clastos ni inclusiones para poder definir ninguna textura heredada, se define pues como de textura cristalina.

Tipo D: se caracterizada por una matriz microcristalina de cristales euédricos de microcuarzo con extinción ondulante y textura heredada de tipo Wackestone. Se han identificado bioclastos de naturaleza marina, como foraminíferos y oolitos. Los oolitos son partículas carbonáticas esferoidales, con una estructura formada por un núcleo envuelto en láminas carbonatadas y de un tamaño inferior a los $2 \mathrm{~mm}$, generalmente formados por calcita o aragonita en ambientes de alta energía. De origen sedimentario, se forman en aguas limpias, cálidas y agitadas de mar poco profundo (Riba 1997: 814). En este caso, el estudio microscópico ha corroborado el análisis macroscópico previo (Figura 6). Este tipo se desmarca geológicamente de los anteriormente descritos, ya que tendría su origen en un medio marino, hecho que enriquece la investigación porque pone de relieve la variabilidad de tipos de sílex utilizados en el abrigo de la Roureda.

\section{Resultados}

Tres de las cuatro variedades de sílex identificadas se han definido por sus características texturales con una aptitud para la talla "de buena a muy buena”. A partir de la clasificación tipológica de los materiales se ha procedido a cuantificar el número de piezas de una misma variedad y se han definido dos tipos de relaciones, la primera: variedad-tipo de soporte retocado y la segunda: variedad-tipo de útil. 

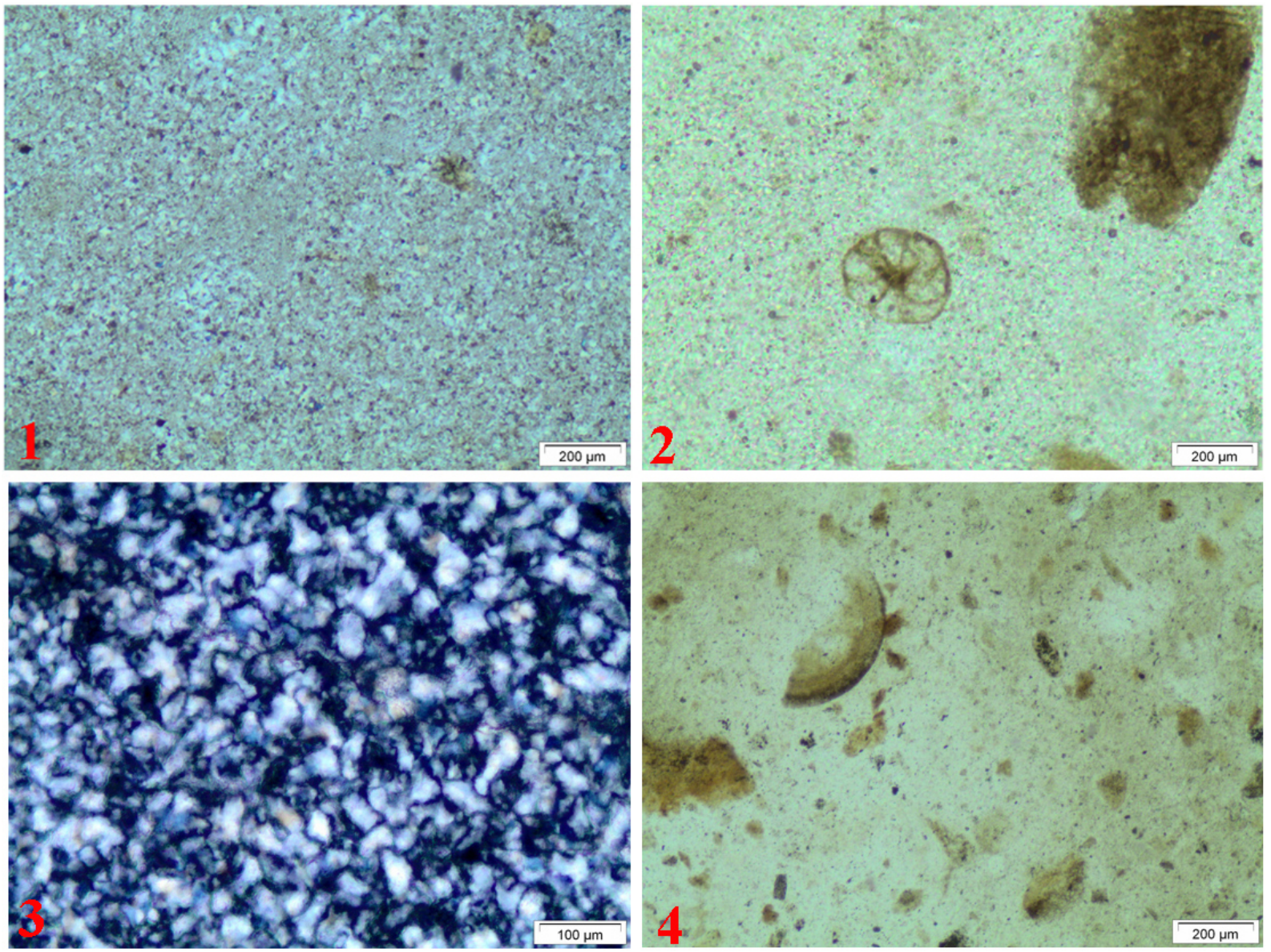

Figura 6. 1. Tipo A. Matriz microcristalina de microcuarzo que pertenece a la muestra arqueológica núm. 2-2 (microscopio óptico). 2. Tipo B. Foraminífero espiralado hallado en la muestra arqueológica núm. 1-7 (microscopio óptico). 3. Tipo C. Matriz criptocristalina que pertenece a la muestra núm. 4 (microscopio óptico). 4. Tipo D. Fragmento de oolito hallado en la muestra arqueológica núm. 5 (microscopio óptico). Comunicación oral del Dr. Carles Martin-Closas en 2015.

Figure 6. 1. Type A. Microcrystalline quartz matrix observed in archaeological sample n. 2-2 (optical microscope) 2. Type B. Spiralled foraminifera observed in archaeological sample n. 1-7 (optical microscope) 3. Type C. Cryptocrystalline matrix observed in archaeological sample n. 4. 4. Type D. Oolite fragment observed in archaeological sample n. 5 (optical microscope). Oral communication with Dr. Carles Martín-Closas in 2015.

\subsection{Relación Variedad- Tipo de soporte retocado}

Han sido analizados los ocho tipos de soporte que se utilizaron para la elaboración de piezas retocadas: lasca, lasca laminar, lámina, laminita, producto de acondicionamiento del núcleo (PAN), golpe de buril, informe + debris y lasca térmica (Tabla 5 y Figura 7).

Recordemos que la variedad más utilizada para la confección de útiles retocados es el Tipo A-I (30,07\%), seguido de: A-II (23,43\%), B (19,23\%), D (15,38\%) y C (4,20\%). Para un estudio más detallado hemos analizado la relación entre las lascas, lascas laminares, láminas y laminitas en relación a los Tipos A, B, C y D, porque numéricamente son los soportes más representativos. El resto de piezas se han tenido en cuenta solamente para el recuento total que precede este párrafo, ya que se trata de soportes de uso muy puntual (PAN y golpe de buril) o fragmentos (informes o lascas térmicas).

Una de las primeras observaciones es que las variedades A-I y A-II tienen un comportamiento similar y muestran grandes similitudes numéricas en cuanto al tipo de soporte retocado, ya que en el caso de lascas laminares, láminas y laminitas obtienen unos resultados muy parecidos (10-14-38 y 9-12-35) respectivamente. En cambio, las 20 lascas de A-I casi duplican las 11 de A-II. 
Tabla 5. Variedades de silex material retocado. Tipo de soportes retocados en relación al tipo de sílex.

Table 5. Varieties of retouched chert material. Type of retouched support in relation to chert types.

\begin{tabular}{|c|c|c|c|c|c|c|c|c|c|c|c|c|c|c|}
\hline \multirow{3}{*}{$\begin{array}{l}\text { Variedad } \\
\text { Soporte }\end{array}$} & \multicolumn{4}{|c|}{ Tipo A } & \multirow{2}{*}{\multicolumn{2}{|c|}{ Tipo B }} & \multirow{2}{*}{\multicolumn{2}{|c|}{ Tipo C }} & \multirow{2}{*}{\multicolumn{2}{|c|}{ Tipo D }} & \multirow{2}{*}{\multicolumn{2}{|c|}{$\begin{array}{c}\text { Indeterminados - } \\
\text { Patinados }\end{array}$}} & \multirow{2}{*}{\multicolumn{2}{|c|}{ Totales }} \\
\hline & \multicolumn{2}{|c|}{ I } & \multicolumn{2}{|c|}{ II } & & & & & & & & & & \\
\hline & núm. & $\%$ & núm. & $\%$ & núm. & $\%$ & núm. & $\%$ & núm. & $\%$ & núm. & $\%$ & núm. & $\%$ \\
\hline Lasca & 20 & 28,57 & 11 & 15,71 & 16 & 22,86 & 0 & 0,00 & 16 & 22,86 & 7 & 10,00 & 70 & 24,48 \\
\hline Lasca laminar & 10 & 18,52 & 9 & 16,67 & 14 & 25,93 & 1 & 1,85 & 17 & 31,48 & 3 & 5,56 & 54 & 18,88 \\
\hline Lámina & 14 & 33,33 & 12 & 28,57 & 11 & 26,19 & 2 & 4,76 & 2 & 4,76 & 1 & 2,38 & 42 & 14,69 \\
\hline Laminita & 38 & 33,93 & 35 & 31,25 & 13 & 11,61 & 9 & 8,04 & 7 & 6,25 & 10 & 8,93 & 112 & 39,16 \\
\hline PAN & 2 & 66,67 & 0 & 0,00 & 1 & 33,33 & 0 & 0,00 & 0 & 0,00 & 0 & 0,00 & 3 & 1,05 \\
\hline Golpe de buril & 1 & 100,00 & 0 & 0,00 & 0 & 0,00 & 0 & 0,00 & 0 & 0,00 & 0 & 0,00 & 1 & 0,35 \\
\hline Informe + Debris & 1 & 33,33 & 0 & 0,00 & 0 & 0,00 & 0 & 0,00 & 1 & 33,33 & 1 & 33,33 & 3 & 1,05 \\
\hline Lasca térmica & 0 & 0,00 & 0 & 0,00 & 0 & 0,00 & 0 & 0,00 & 1 & 100,00 & 0 & 0,00 & 1 & 0,35 \\
\hline & 86 & 30,07 & 67 & 23,43 & 55 & 19,23 & 12 & 4,20 & 44 & 15,38 & 22 & 7,69 & 286 & 100,00 \\
\hline
\end{tabular}




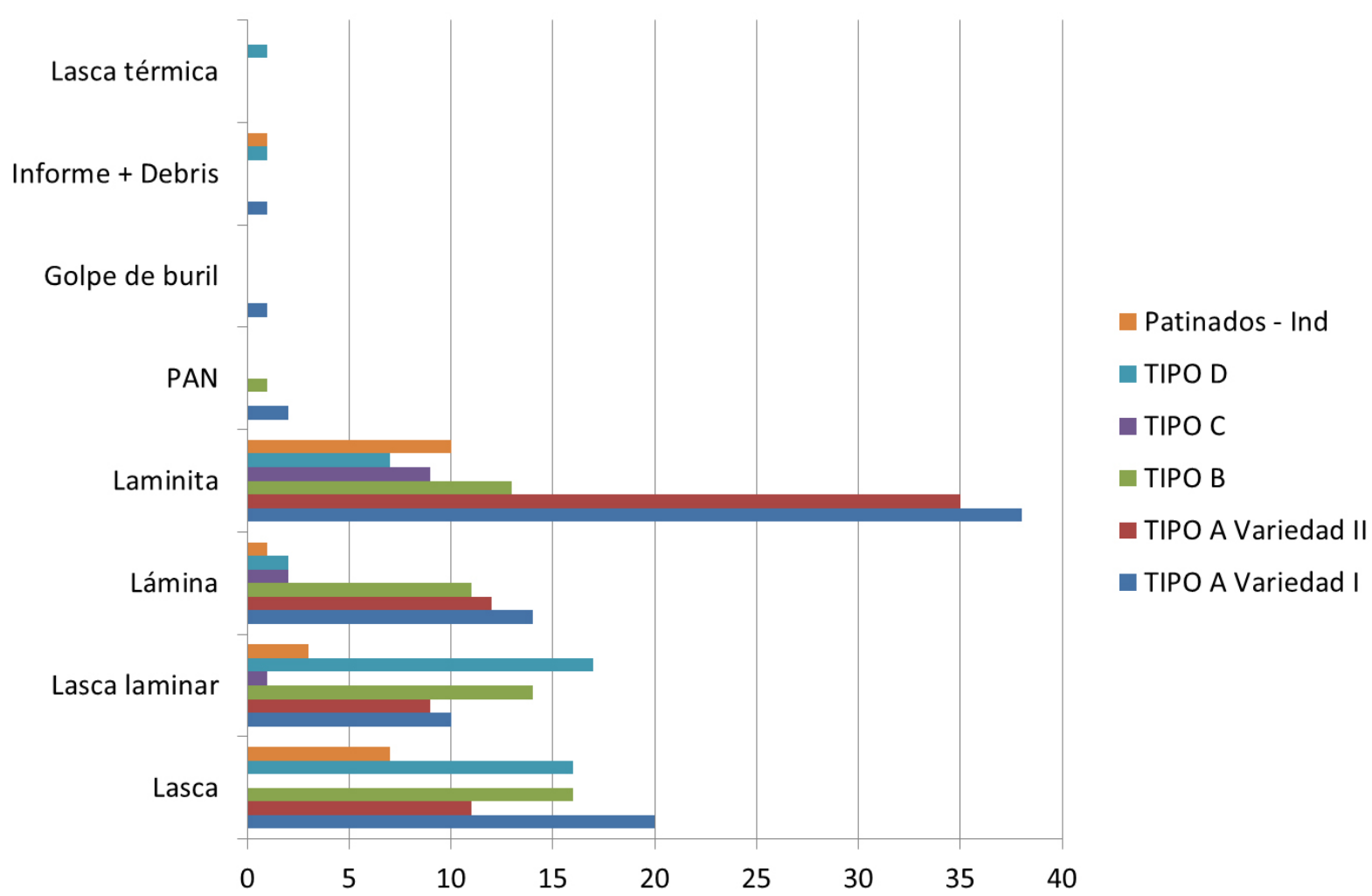

Figura 7. Gráfica que relaciona el tipo de soportes retocados en relación al tipo de sílex. Figure 7. Type of retouched support in relation to chert types graphic.

El Tipo B es semejante en número de lascas y láminas al Tipo A (16-11), pero numéricamente superior en lascas laminares (14) y muy por debajo en cuanto a laminitas (13).

El Tipo C se presenta principalmente como materia prima para fabricar soportes microlaminares (9). La ausencia de núcleos y la escasez de lascas entre los materiales no retocados (11) de esta variedad, podría indicar que la fabricación de los soportes se realizaría en otro lugar, ya que generalmente en los esquemas de talla documentados en el yacimiento se generan lascas de configuración o mantenimiento de los núcleos que suelen ser reutilizadas en la confección de utillaje retocado. Las 19 láminas no retocadas de este tipo podrían considerarse la evidencia de unos soportes que llegan al yacimiento ya tallados.

El Tipo D destaca especialmente en el recurso a soportes retocados de tipo lasca (16) y lascas laminares (17) para la confección del utillaje, siendo mucho menor su importancia en cuanto a retocados sobre laminitas (7) o láminas (2), hecho que podemos atribuir a una aptitud para la talla menor (Tabla 5).

\subsection{Relación Variedad-Tipo de útil}

En relación a los grupos tipológicos observamos que existen pequeñas variaciones dependiendo de la variedad (Tabla 6). En el cómputo global el Tipo A, es el más abundante, y junto al Tipo B se han utilizado para fabricar la mayor parte de los útiles líticos. Los Tipos C y $\mathrm{D}$, que son los menos abundantes, poseen datos un tanto diferentes a los dos Tipos principales. El Tipo C, con tan solo 12 piezas retocadas, parece que se ha utilizado principalmente para la fabricación de utillaje microlaminar. Por su parte, el Tipo D, al igual que los dos primeros, presenta una utilización más repartida, aunque destaca que muchas de las piezas incluidas en "Diversos", que en su mayoría son útiles fracturados de los que no podemos confirmar su tipología. 
Tabla 6. Análisis tecno-tipológico de la industria lítica en relación a los tipos de sílex.

Table 6. Techno-typological analysis of lithic industry in relation to chert types.

\begin{tabular}{|c|c|c|c|c|c|c|c|c|c|c|c|c|c|}
\hline \multirow{3}{*}{ Variedad } & \multicolumn{4}{|c|}{ Tipo A } & \multirow{2}{*}{\multicolumn{2}{|c|}{ Tipo B }} & \multirow{2}{*}{\multicolumn{2}{|c|}{ Tipo C }} & \multirow{2}{*}{\multicolumn{2}{|c|}{ Tipo D }} & \multirow{2}{*}{\multicolumn{2}{|c|}{$\begin{array}{c}\text { Indeterminados - } \\
\text { Patinados }\end{array}$}} & \multirow[t]{3}{*}{ Totales } \\
\hline & & I & & II & & & & & & & & & \\
\hline & núm. & $\%$ & núm. & $\%$ & núm. & $\%$ & núm. & $\%$ & núm. & $\%$ & núm. & $\%$ & \\
\hline Raspadores & 4 & 4,65 & 4 & 5,97 & 9 & 16,36 & 1 & 8,33 & 2 & 4,55 & 4 & 18,18 & 24 \\
\hline Perforadores & 1 & 1,16 & 0 & 0,00 & 2 & 3,64 & 0 & 0,00 & 0 & 0,00 & 0 & 0,00 & 3 \\
\hline Buriles & 4 & 4,65 & 2 & 2,99 & 1 & 1,82 & 0 & 0,00 & 2 & 4,55 & & 0,00 & 9 \\
\hline Piezas retocadas & 5 & 5,81 & 1 & 1,49 & 10 & 18,18 & 0 & 0,00 & 5 & 11,36 & 2 & 9,09 & 23 \\
\hline Truncaduras & 15 & 17,44 & 16 & 23,88 & 7 & 12,73 & 1 & 8,33 & 6 & 13,64 & 5 & 22,73 & 50 \\
\hline Dorsos & 5 & 5,81 & 2 & 2,99 & 1 & 1,82 & 0 & 0,00 & 0 & 0,00 & 0 & 0,00 & 8 \\
\hline Muescas-Denticulados & 10 & 11,63 & 9 & 13,43 & 9 & 16,36 & 1 & 8,33 & 0 & 0,00 & 1 & 4,55 & 30 \\
\hline Piezas astilladas & 0 & 0,00 & 1 & 1,49 & 1 & 1,82 & 0 & 0,00 & 1 & 2,27 & 0 & 0,00 & 3 \\
\hline Microburiles & 0 & 0,00 & 0 & 0,00 & 1 & 1,82 & 0 & 0,00 & 0 & 0,00 & 0 & 0,00 & 1 \\
\hline Diversos & 5 & 5,81 & 3 & 4,48 & 0 & 0,00 & 0 & 0,00 & 19 & 43,18 & 2 & 9,09 & 29 \\
\hline Raederas & 1 & 1,16 & 0 & 0,00 & 0 & 0,00 & 0 & 0,00 & 0 & 0,00 & 0 & 0,00 & 1 \\
\hline TOTAL & 86 & 100,00 & 67 & 100,00 & 55 & 100,00 & 12 & 100,00 & 44 & 100,00 & 22 & 100,00 & 286 \\
\hline
\end{tabular}


Estos datos evidencian que tanto el Tipo A como el Tipo B, y posiblemente el Tipo D, pese a las diferencias observadas en su calidad para la talla, fueron ampliamente usados, aunque como veremos más adelante con objetivos distintos. El Tipo C, en cambio, podría tener una explotación más específica, centrada en los útiles microlaminares.

Si observamos el gráfico basado en el número de útiles tallados por grupo tipológico en función de los Tipos podemos extraer varias conclusiones:

Las dos variedades del Tipo A continúan teniendo muchas similitudes en cuanto a su utilización, y para la configuración de: raspadores, muescas-denticulados, compuestos y útiles microlaminares. Por lo tanto, presentan un comportamiento muy parecido.

El Tipo B es menos utilizado en comparación con el tipo anterior, aunque se utiliza también para la elaboración de una amplia diversidad de útiles.

El Tipo C, pese a ser el más escaso en efectivos, nos aporta un dato más que significativo. Se trata de una variedad utilizada casi exclusivamente en soportes laminares y útiles microlaminares (75\%). Este dato, junto con la ausencia de núcleos, nos inclina a pensar que esta materia prima podría haber llegado al yacimiento bajo forma de láminas y laminitas. Siendo su calidad elevada, pero similar a la de otros tipos presentes en mayor número en el yacimiento, se nos plantea la cuestión de intentar explicar su presencia. Las respuestas son potencialmente diversas, desde que podría tratarse de piezas obtenidas por intercambio con otros grupos, hasta que podría tratarse de materiales que, por su escasez, o su aspecto, se dotaran de alguna connotación especial.

Por último, destacaremos que el Tipo D presenta en cuanto a soportes retocados un número similar en lascas (16) y lascas laminares (17) a las dos variedades más abundantes (Tipos A y B). En cambio, el utillaje retocado en soporte lámina o laminita en ésta variedad silícea es escaso. La mayoría de las piezas retocadas fabricadas sobre el Tipo D están fracturadas y tipológicamente se integran en "Diversos". De hecho, hemos comprobado que de estas piezas, aquellas que podríamos incluir -con dudas- en algún grupo tipológico (unas 12), se reparten entre los raspadores, las piezas con retoques en los bordes y los útiles microlaminares. La elevada fracturación e indeterminación de los útiles elaborados sobre el Tipo D debería ponerse en relación probablemente con la aptitud a la talla de la materia prima. Pese a esta última afirmación, si distribuimos las piezas retocadas en dos categorías: útiles domésticos y proyectiles (Tabla 7), observaremos tres agrupaciones diferenciadas. En primer lugar, el Tipo A, que presenta el mismo porcentaje en ambas categorías; en segundo lugar, el Tipo $\mathrm{C}$, que como hemos indicado anteriormente se orienta a la obtención de proyectiles, y en tercer lugar, los Tipos $\mathrm{B}$ y $\mathrm{D}$, donde dominan claramente los útiles domésticos.

Tabla 7. Relación entre utillaje doméstico y proyectiles en función del tipo de sílex.

Table 7. Quantitative relation between domestic tooling and projectiles in relation to chert type.

\begin{tabular}{|c|c|c|c|c|c|}
\hline Grupos & $\begin{array}{l}\mathbf{A} \\
\mathrm{I}\end{array}$ & II & B & $\mathrm{C}$ & $\mathbf{D}$ \\
\hline Proyectiles & $49,4 \%$ n. 40 & 46,9\% n.30 & 27,3 \% n.15 & $75 \%$ n.9 & $24 \%$ n.6 \\
\hline Domésticos & $50,6 \%$ n. 41 & $53,1 \%$ n.34 & $72,7 \%$ n.40 & $25 \%$ n.3 & $76 \%$ n.19 \\
\hline
\end{tabular}

En conclusión, todos estos datos parecen indicar un uso distinto de las diversas variedades de sílex que hemos definido:

El Tipo A, que fue utilizado para la fabricación de toda suerte de útiles, siendo posiblemente los proyectiles su objetivo prioritario y reutilizándose las lascas secundarias para la elaboración de útiles domésticos. La buena aptitud de la materia prima y su relativa proximidad al asentamiento debieron jugar un papel determinante para su aprovechamiento. 
El Tipo B se utilizó principalmente para la fabricación de útiles domésticos, aunque los proyectiles están bien representados. Se trata de una variedad de buena calidad y relativamente cercana al asentamiento.

El Tipo C, de textura cristalina y coloración peculiar fue utilizado básicamente para la elaboración de proyectiles. Posiblemente su llegada al yacimiento se realizó bajo forma de soporte ya tallado.

El Tipo D presenta un uso similar al Tipo B, predominando el utillaje doméstico. Recordemos que se trata de la variedad de peor calidad, lo que podría explicar la elevada cantidad de útiles fracturados sobre esta materia prima.

\section{Origen y posibles áreas de captación de recursos}

\subsection{Análisis geológico y análisis cartográfico del entorno}

El análisis arqueopetrológico de los materiales del yacimiento se ha completado con los trabajos de contextualización geológica y geográfica de las áreas-fuente silíceas potenciales, tanto a través del análisis de la cartografía geológica de la región (IGME 2000) como con varias prospecciones sobre el terreno que han cubierto distintas zonas de las comarcas del Maestrat y de Els Ports, ya que apenas existe literatura científica sobre la disponibilidad de sílex en el territorio (IGME 2000; Arasa Tuliesa 2011) también hemos recurrido a las informaciones orales de los habitantes de la zona. El análisis se ha efectuado en un radio de hasta $100 \mathrm{~km}$, desarrollando así un exhaustivo y sistemático trabajo sobre el terreno a corta, media y larga distancia del yacimiento, para obtener una idea de conjunto y global del entorno geológico y la disponibilidad de afloramientos de sílex. En total se han visitado y recogido muestras de 8 puntos de afloramiento de rocas silíceas (Figura 8).

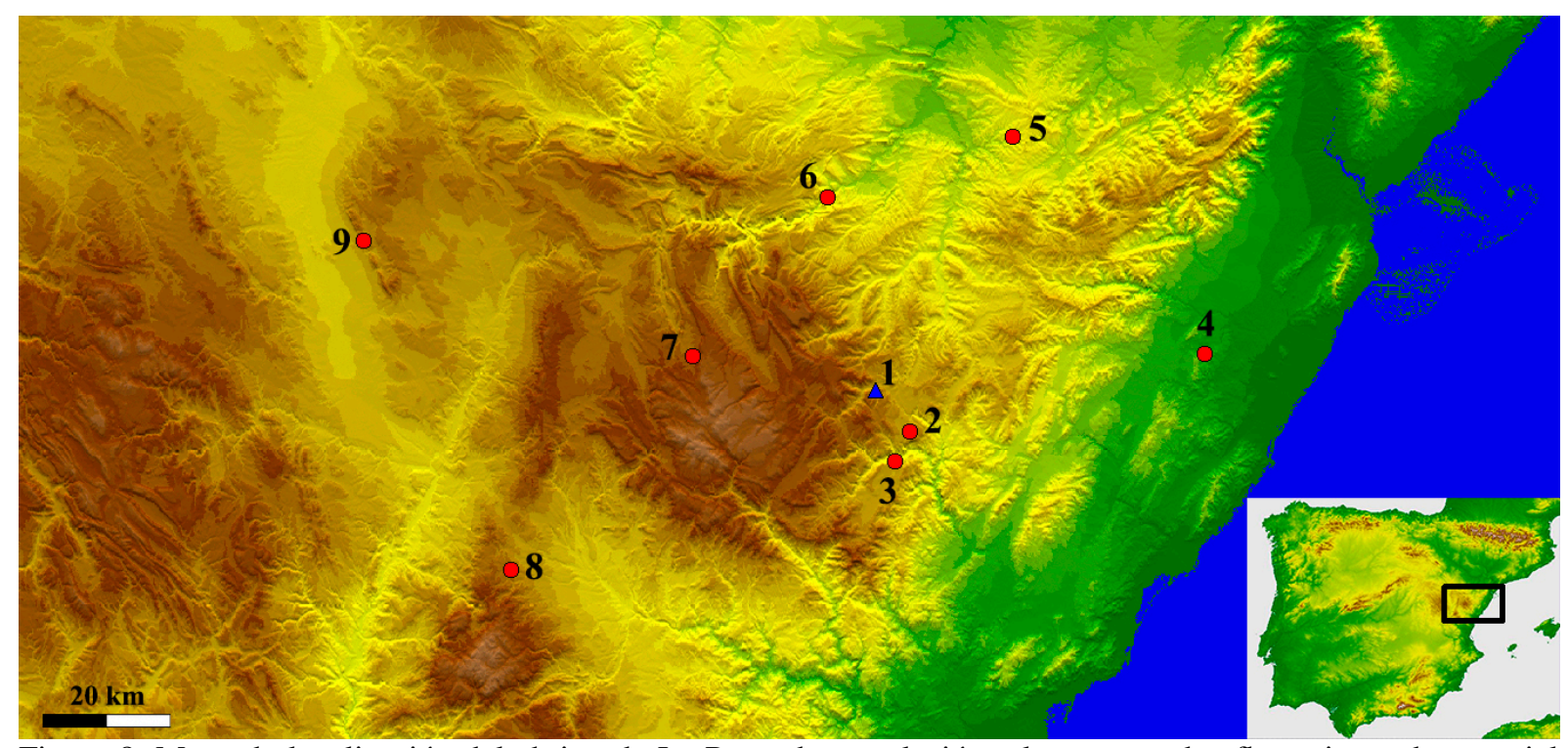

Figura 8. Mapa de localización del abrigo de La Roureda en relación a los puntos de afloramiento de material silíceo hallados en las diferentes prospecciones. 1. Roureda; 2. Mas del Pinar; 3. Mas de Quinyó; 4. Font de la Salut; 5. Fontdespatlla; 6. Guadalope; 7. Fortanete; 8. Camarena; 9. Chelva.

Figure 8. La Roureda’s Rockshelter location map in relation to siliceous material collected in several geological surveys. 1. La Roureda; 2. Mas del Pinar; 3. Mas de Quinyó; 4. Font de la Salut; 5. Fontdespatlla; 6. Guadalope; 7. Fortanete; 8. Camarena; 9. Chelva. 


\subsubsection{Mas del Pinar}

Es un afloramiento secundario antropizado por la labranza actual. Se halla tan sólo a 5 $\mathrm{km}$ al norte del abrigo, siendo el afloramiento más cercano al yacimiento y en el que se recuperan abundantes fragmentos de sílex.

\subsubsection{Mas del Quinyó}

El lugar situado a unos $10 \mathrm{~km}$ de la Roureda pertenece a la Fm C21-26 del Turoniense, formada por dolomías, margodolomías y calizas bien estratificadas, Hoja 569 "Mosqueruela" (IGME 2000). El afloramiento presenta material en posición primaria y secundaria. El encajante es una caliza con estratificación centimétrica, que contiene abundante sílex de coloraciones oscuras y con pátina, tanto en sus formas nodulares como estratificadas.

\subsubsection{Sinclinal de Fortanete}

El tramo Maestrichtiense - Paleoceno, es un conjunto carbonatado y finalmente detrítico de origen salobre o lacustre que marca el retroceso detrítico del mar, Hoja 543 "Villarluego" (IGME 2000). El estrato calizo que contiene lechos de sílex nodular aflora en una ancha cubeta de $8 \mathrm{~km}$ de ancho por 20 de largo. El estrato calizo es de fácil acceso y se hallan frecuentes nódulos de sílex. El sinclinal de Fortanete se halla a $22 \mathrm{~km}$ de distancia al yacimiento.

\subsubsection{Font de la Salut}

La Fm eoceno-oligocena, Hoja 521 "Beceite” (IGME 2000) se describe como "un conjunto detrítico formado por areniscas [...] donde es frecuente encontrar niveles de conglomerados calcáreos, así como pequeños niveles carbonatados con sílex que contienen tallos de carófitas y abundantes tallos de ostrácodos y gasterópodos". El afloramiento se halla a $45 \mathrm{~km}$ de distancia de la Roureda y a él se accede fácilmente. Se localizan abundantes nódulos aunque su extracción es dificultosa por la naturaleza del encajante.

\subsubsection{Fondespatlla}

Arasa Tuliesa (2011) documenta que en los alrededores de Fondespatlla afloran un centenar de metros de carbonatos de agua dulce que contienen nódulos de sílex, restos de fauna y algunos gasterópodos. Se observan también intercalaciones de niveles de lutitas rosadas y calizas en niveles masivos interpretándose como un medio palustre situado en una llanura lutítica deprimida que forma parte del Grupo Matarraña - Guadalope. En la Hoja 520 "Peñarroya de Tastavins" (IGME 2000), se identifican como la Fm TA3-BC31-1 de edad oligocena (Chatiense, Estampiense y Sannoisiense) de conglomerados poligénicos de cemento calcáreo con intercalaciones de areniscas y arcillas rojas. El sílex es poco abundante, se halla en forma de nódulos $(2-5 \mathrm{~cm})$ de extracción difícil. La distancia de este afloramiento hasta la Roureda es de $68 \mathrm{~km}$.

\subsubsection{Formación Chelva}

Según la bibliografía geológica , Hojas: 590 “Puebla de Valverde”, 567 “Teruel” y 542 “Alfambra” (IGME 2000) se trata de una formación de calizas y calcarenitas estratificadas con nódulos de sílex, de edad comprendida entre el Toarciense superior al Oxfordiense superior y una potencia de $25 \mathrm{~m}$. El afloramiento de fácil acceso y sílex muy abundante pero de extracción difícil de la roca caja fue localizado en la Sierra del Pobo, a 75 km de distancia de la Roureda. 


\subsubsection{Río Guadalope}

En la Hoja 519 “Aguaviva” (IGME 2000) se trata de un afloramiento secundario, correspondiente a la terraza cuaternaria de aluviones que se halla en el río Guadalope a la altura del barrio de Ladruñán. Los nódulos decimétricos son abundantes. Este afloramiento se encuentra a $81 \mathrm{~km}$ de distancia de la Roureda.

\subsubsection{Camarena}

La Hoja 613 “Camarena de la Sierra” (IGME 2000) presenta la Fm de "caliza arenosa parda o marrón con juntas onduladas y figuras digitadas de disolución, hacia la base, localmente, aparecen abundantes nódulos arriñonados de sílex de color crema y pardo o gris ceniza". En el afloramiento localizado el sílex es escaso y de difícil extracción. La distancia de este afloramiento a la Roureda de 87 km (Tabla 8).

\subsection{Análisis arqueopetrológico material geológico}

Se han caracterizado un total de 12 muestras que han podido relacionarse con distintos tipos de sílex.

Las características texturales de dos de las muestras procedentes del afloramiento secundario de Mas del Pinar tienen una gran similitud con las características descritas para las dos variedades del Tipo A, algunas de las muestras procedentes de los conglomerados de Font de la Salut presentan también gran similitud con A-II , mientras que las muestras procedentes de las calizas de Fortanete se relacionan con A-I. Valorando la dificultad de extracción de la materia prima entre los distintos afloramientos y la distancia del abrigo a los mismos, se podría considerar que, por menor gasto energético, el afloramiento más favorable para la recolección y abastecimiento de sílex sería Mas del Pinar, situado a tan sólo 5 km del abrigo y con material abundante, aunque no podemos descartar la explotación de Font de la Salut y Fortanete.

La materia prima que por sus características se asemeja en mayor medida al Tipo B es la proporcionada por el afloramiento de Mas del Quinyó, a tan sólo $10 \mathrm{~km}$ de distancia al abrigo de la Roureda.

No hemos localizado por el momento ningún representante geológico relacionable con los Tipos C y D, por lo deberemos continuar la búsqueda para completar este estudio. 
Tabla 8. Cuadro-resumen de los afloramientos, incluyendo sus principales características, tipos de sílex recolectados y sus características macroscópicas y microscópicas. Table 8. Outcrop's summary, including their main characteristics, types of flint collected and its macroscopic and microscopic observations.

\begin{tabular}{|c|c|c|c|c|c|c|c|c|}
\hline Afloramiento & $\begin{array}{l}\text { Distancia } \\
\text { al abrigo } \\
\text { de La } \\
\text { Roureda }\end{array}$ & $\begin{array}{l}\text { Tipo de } \\
\text { afloramiento }\end{array}$ & Contexto & Abundante & Medidas & $\begin{array}{l}\text { Caracterización } \\
\text { macroscópica }\end{array}$ & $\begin{array}{l}\text { Carcterización } \\
\text { microscópica }\end{array}$ & Origen \\
\hline Mas del Pinar & $5 \mathrm{~km}$ & $\begin{array}{l}\text { afloramiento } \\
\text { secundario }\end{array}$ & $\begin{array}{l}\text { muy fácil } \\
\text { extracción, suelo } \\
\text { antropizado }\end{array}$ & $\begin{array}{l}\text { muy } \\
\text { abundante }\end{array}$ & $8-10 \mathrm{~cm}$ & $\begin{array}{l}\text { mudstone, marrón claro, } \\
\text { homogéneo, calidad } \\
\text { buena, grano muy fino, } \\
\text { azoico. }\end{array}$ & $\begin{array}{l}\text { mudstone - } \\
\text { wackestone, } \\
\text { homogéneo, matriz } \\
\text { de microcuarzo, } \\
\text { restos de } \\
\text { foraminífero. }\end{array}$ & $\begin{array}{l}\text { ambiente de } \\
\text { transición = tipo } \\
\text { A variedad I y } \\
\text { variedad II }\end{array}$ \\
\hline $\begin{array}{l}\text { Mas del } \\
\text { Quinyó }\end{array}$ & $10 \mathrm{~km}$ & $\begin{array}{l}\text { afloramiento } \\
\text { primario }\end{array}$ & $\begin{array}{l}\text { de extracción } \\
\text { fácil - regular; } \\
\text { roca caja } \\
\text { margodolomíass } \\
\text { y calizas o } \\
\text { dolomía }\end{array}$ & abundante & $10-15 \mathrm{~cm}$ & $\begin{array}{l}\text { wackestone, marrón } \\
\text { oscuro a nego; } \\
\text { heterogéneo, restos } \\
\text { bioclásticos de } \\
\text { gasterópodo y carófitas. } \\
\text { pátina blanca, } \\
\text { translúcido, con } \\
\text { recristalizaciones, grano } \\
\text { muy fino a medio, de } \\
\text { buena calidad. } \\
\text { estratificado y nodular. }\end{array}$ & $\begin{array}{l}\text { wackestone, relictos } \\
\text { fósiles } \\
\text { indeterminados } \\
(10 \%) \text {, fragmentos } \\
\text { de carófitas (10\%), } \\
\text { matriz de micro- } \\
\text { criptocuarzo (80\%) }\end{array}$ & $\begin{array}{l}\text { ambiente de } \\
\text { transición = tipo } \\
\text { B }\end{array}$ \\
\hline Fortanete & $22 \mathrm{~km}$ & $\begin{array}{l}\text { afloramiento } \\
\text { primario }\end{array}$ & $\begin{array}{l}\text { de muy difícil } \\
\text { extracción; roca } \\
\text { caja calizas }\end{array}$ & $\begin{array}{l}\text { regularmente } \\
\text { abundante }\end{array}$ & $3-5 \mathrm{~cm}$ & $\begin{array}{l}\text { mudstone, marrón } \\
\text { oscuro a negro, } \\
\text { homogéneo, de buena } \\
\text { calidad, grano muy fino, } \\
\text { azoico, patinación leve. }\end{array}$ & $\begin{array}{l}\text { mudstone- } \\
\text { wackestone, matriz } \\
\text { de microcuarzo, } \\
\text { homogéneo, restos } \\
\text { de ostrácodo } \\
\text { aislados. }\end{array}$ & $\begin{array}{l}\text { ambiente de } \\
\text { transición = } \\
\text { salobre y o } \\
\text { lacustre } \\
\text { Tipo A variedad } \\
\text { I }\end{array}$ \\
\hline $\begin{array}{l}\text { Font de la } \\
\text { Salut }\end{array}$ & $45 \mathrm{~km}$ & $\begin{array}{l}\text { afloramiento } \\
\text { primario }\end{array}$ & $\begin{array}{l}\text { de muy difícil } \\
\text { extracción; roca } \\
\text { caja } \\
\text { conglomerado }\end{array}$ & $\begin{array}{l}\text { regularmente } \\
\text { abundante }\end{array}$ & $1-10 \mathrm{~cm}$ & $\begin{array}{l}\text { mudstone, marrón claro, } \\
\text { homogéneo, de buena } \\
\text { calidad, grano muy fino, } \\
\text { pátina superficial, }\end{array}$ & $\begin{array}{l}\text { mudstone, matriz de } \\
\text { microcuarzo, } \\
\text { materia orgánica } \\
\text { abundante }\end{array}$ & $\begin{array}{l}\text { ambiente de } \\
\text { transición = } \\
\text { Tipo A variedad } \\
\text { II }\end{array}$ \\
\hline
\end{tabular}




\begin{tabular}{|c|c|c|c|c|c|c|c|c|}
\hline Fondespatlla & $50 \mathrm{~km}$ & $\begin{array}{l}\text { afloramiento } \\
\text { primario }\end{array}$ & $\begin{array}{l}\text { de muy difícil } \\
\text { extracción; roca } \\
\text { caja carbonatos }\end{array}$ & raro & $2-5 \mathrm{~cm}$ & $\begin{array}{l}\text { mudstone, marrón } \\
\text { claro, homogéneo, de } \\
\text { mediocre a buena } \\
\text { calidad, grano muy fino } \\
\text { a fino, azoico, } \\
\text { patinación leve, en } \\
\text { proceso de } \\
\text { calcedonización. }\end{array}$ & $\begin{array}{l}\text { calcedonia length } \\
\text { fast, }(5 \%), \text { matriz de } \\
\text { microcuarzo (85\%), } \\
\text { minerales isótropos } \\
(10 \%)\end{array}$ & $\begin{array}{l}\text { sin coincidencia } \\
\text { origen marino }\end{array}$ \\
\hline Chelva & $75 \mathrm{~km}$ & $\begin{array}{l}\text { afloramiento } \\
\text { primario }\end{array}$ & $\begin{array}{l}\text { de muy difícil } \\
\text { extracción; roca } \\
\text { caja carbonatos }\end{array}$ & $\begin{array}{l}\text { muy } \\
\text { abundante }\end{array}$ & $4-15 \mathrm{~cm}$ & $\begin{array}{l}\text { wackestone, gris claro y } \\
\text { gris rojizo, heterogéno, } \\
\text { calidad mediocre, grano } \\
\text { grueso a fino, azoico, } \\
\text { patinación leve, con } \\
\text { presencia de } \\
\text { pseudomorfos } \\
\text { romboidales, silificación } \\
\text { muy baja. }\end{array}$ & $\begin{array}{l}\text { matriz de } \\
\text { microscuarzo (45\%), } \\
\text { restos bioclásticos } \\
\text { silificados ( } 25 \%), \\
\text { pseudomorfos } \\
\text { romboidales muy } \\
\text { abundates (30\%) }\end{array}$ & $\begin{array}{l}\text { sin coincidencia } \\
\text { origen marino }\end{array}$ \\
\hline $\begin{array}{l}\text { Río } \\
\text { Guadalope }\end{array}$ & $81 \mathrm{~km}$ & $\begin{array}{l}\text { afloramiento } \\
\text { secundario }\end{array}$ & $\begin{array}{l}\text { de muy fácil } \\
\text { extracción; Ilera } \\
\text { del río }\end{array}$ & abundante & $5-10 \mathrm{~cm}$ & $\begin{array}{l}\text { mudstone, marrón } \\
\text { oscuro a negro, } \\
\text { homogéneo, de buena } \\
\text { a muy buena calidad, de } \\
\text { grano fino a muy fino, } \\
\text { azoico, en proceso de } \\
\text { calcedonización. }\end{array}$ & $\begin{array}{l}\text { matriz de } \\
\text { microcuarzo (90\%), } \\
\text { calcedonia (5\%), } \\
\text { materia } \\
\text { orgánica(5\%). }\end{array}$ & $\begin{array}{l}\text { ambiente de } \\
\text { transición = } \\
\text { Tipo A variedad } \\
\text { I }\end{array}$ \\
\hline Camarena & $87 \mathrm{~km}$ & $\begin{array}{l}\text { afloramiento } \\
\text { primario }\end{array}$ & $\begin{array}{l}\text { de muy difícil } \\
\text { extracción, roca } \\
\text { caja calizas }\end{array}$ & $\begin{array}{l}\text { regularmente } \\
\text { abundante }\end{array}$ & $3-5 \mathrm{~cm}$ & $\begin{array}{l}\text { packstone, gris rojizo, } \\
\text { heterogéneo, de calida } \\
\text { baja a mediocre, de } \\
\text { grano fino a grueso, } \\
\text { restos bioclásticos, muy } \\
\text { baja silificación. }\end{array}$ & $\begin{array}{l}\text { matriz de } \\
\text { microscuarzo (65\%), } \\
\text { restos bioclásticos } \\
\text { (espículas, } \\
\text { gasterópodos) } \\
\text { (30\%), óxidos } \\
\text { metálicos (4\%), } \\
\text { ooides }(1 \%)\end{array}$ & $\begin{array}{l}\text { sin coincidencia } \\
\text { origen marino }\end{array}$ \\
\hline
\end{tabular}




\section{Conclusiones}

El análisis macroscópico de 286 piezas retocadas, 2.753 restos de talla y 20 núcleos nos ha permitido establecer 4 variedades distintas de sílex que gracias al estudio microscópico hemos podido contrastar y caracterizar texturalmente. Dichas variedades son en su mayoría de origen salobre o lacustre, dato que concuerda con los resultados obtenidos en las prospecciones sobre el territorio; así, por un lado, podemos situar geológicamente el Tipo A, localizándolo al menos en 3 afloramientos situados en un radio local y regional (Mas del Pinar, Font de la Salut y Fortanete). Por otro lado, determinados sílex geológicos comparables con el Tipo B -segundo en número de efectivos identificados en el yacimiento- han sido hallados a $10 \mathrm{~km}$ de distancia del abrigo de la Roureda. Por el momento, los afloramientos de los materiales silíceos de los Tipos C y D, mucho menos abundantes en el yacimiento, no han sido localizados, el hecho que tampoco contemos con núcleos de estos tipos, podría relacionarse con una captación indirecta de dichos recursos por intercambio, o bien con una cadena operativa lítica secuenciada temporal o espacialmente, no podemos en cualquier caso tampoco obviar la posibilidad que dichos núcleos se encuentren en zonas del yacimiento aún no excavadas.

En todo caso, el hallazgo de diversos afloramientos de sílex y la discriminación de estos 4 tipos de sílex nos muestra que los pobladores del abrigo contaron con cierta diversidad de recursos abióticos en un radio local y regional, hecho que les permitió la manufactura de todo tipo de útiles. El análisis de la corticalidad de la industria lítica y de los propios núcleos nos ha aportado también una serie de datos. En aquellos tipos presentando un índice de corticalidad relativamente destacado, podemos presuponer el transporte de los nódulos de materia prima al yacimiento (Tipo A-I); en otros casos, parece tratarse de núcleos configurados previamente a su llegada al mismo (Tipo A-II y Tipo B). Finalmente, podemos entrever el uso diferencial de determinadas variedades de sílex, así por ejemplo, el Tipo C aparece casi dedicado en exclusiva a la talla microlaminar, lo que podría indicar su llegada bajo forma de soporte.

La compilación de todos los datos expuestos hasta ahora en este trabajo constituyen el primer estudio y hasta la fecha el más exhaustivo, sobre la economía de los recursos abióticos desarrollada por los grupos humanos de cazadores-recolectores del norte del País Valenciano, aproximándonos al conocimiento sobre el uso del territorio por parte de los pobladores del abrigo de la Roureda y a la interpretación sobre la gestión de sus recursos abióticos.

\section{Agradecimientos}

Este trabajo se ha realizado en el marco de los proyectos de investigación: HAR201455131; SGR2014-00108 y HAR2011-25440.

Queremos agradecer al Espeleo Club de Castelló su ayuda en la localización de algunos afloramientos de materia primas, especialmente a Pepe Viciano, Juan Ramos y Jesús Almela. Así mismo, Gustau Aguilella, del Servei d'Investigacions Arqueològiques i Prehistòriques de la Diputació de Castelló ha colaborado con éstos en la recopilación de los materiales geológicos. También queremos agradecer la ayuda del profesor Ferran Arasa, que no únicamente encontró el yacimiento de la Roureda, si no que aportó algunas localizaciones de sílex en los alrededores del yacimiento. A Jordi Casadellà queremos agradecerle su intensa participación en las prospecciones realizadas. A Luis Miguel García Simón debemos agradecerle la localización de diversos afloramientos en la zona aragonesa que nos han servido para completar la información de este trabajo. 


\section{Referencias}

Arasa Gil, F. 1977, Estudio arqueológico de Vilafranca del Cid (Castellón), Cuadernos de Prehistoria y Arqueología Castellonenses, 4:243- 269. (in Spanish) ("Archaeological study of Vilafranca del Cid (Castellón)") URL: http://hdl.handle.net/10234/50399

Arasa Tuliesa, A. 2011, Roques dels Ports, Col·lecció del Grup de Recerca Científica Terres de l'Ebre Vol. 4, Grup de recerca científica Terres de l’Ebre, Tortosa, 312 p. (en catalán; in Catalan) ("Stones of Els Ports")

Instituto Geológico y Minero de España (IGME) 2000, Mapa Geológico de España, Escala 1:50000, serie MAGNA, Segunda Serie, Primera edición, Madrid, Hojas: sheets 517, 518, 519, 520, 521, 542, 543, 544, 545, 546, 567, 568, 569, 570, 571, 590, 591, 592, 593, 594, 613, 614, 615, 616, \& 617. (in Spanish) (“Geological Map of Spain”)

Luedtke, B. E. 1992, An archaeologist's guide to chert and flint, Archaeological Research Tools, Vol. 7, Institute of Archaeology, University of California, Los Angeles, 156 p. (en inglés; in English) (“Guía del sílex para arqueólogos”)

Mangado, J. 2004, L'arqueopetrologia del sílex, una clau per al coneixement paleoeconòmic i social de les poblacions prehistòriques, Societat Catalana d’Arqueologia, Barcelona, 116 p. (en catalán; in Catalan) ("The archaeopetrology of flint, a key for the palaeconomic and social knowledge of prehistoric populations”)

Mangado, J. 2005, La caracterización y el aprovisionamiento de los recursos líticos en la Prehistoria de Cataluña. Las materias primas silíceas del Paleolítico Superior final y Epipaleolítico. British Archaeological Reports. International Series Vol. 1420, Archaeopress, Oxford, 205 p. (in Spanish) ("The characterisation and procurement of lithic resources in the Prehistory of Catalonia. Siliceous lithic raw materials from the final Upper Palaeolithic and Epipalaeolithic”)

Masson, A. 1979, Recherches sur la provenance des silex préhistoriques. Méthode d'étude, Études Préhistoriques, 15: 29-40. (en francés; in French) ("Research on the origin of prehistoric flint. Method of study")

Mauger, M. 1984, L'apport des microfossiles dans l'identification des silex. Exemple du Magdalénien de l'Ile-de-France, Bulletin Société Préhistorique Française, 81(7): 216220. (en francés; in French) ("The contribution of microfossils in the identification of flint. Example from the Magdalenian of the Ile-de-France”) URL: http://www.persee.fr/doc/bspf_0249-7638_1984_num_81_7_8636

Parcerisas, J. 2006, Una propuesta de análisis multicriterio en el estudio del aprovisionamiento de los recursos líticos. En Sociedades prehistóricas, recursos abióticos y territorio (Martínez, G., Morgado, A. \& Afonso, J.A. Eds.), Fundación Ibn al-jatib de Estudios de Cooperación Cultural, Loja (Granada): p. 33-44. (in Spanish) (“A proposed multi-criteria analysis in the study of procurement of lithic resources”)

Roman, D. 2010, El jaciment epimagdalenià de la Balma de la Roureda (Vilafranca, Els Ports, País Valencià), Pyrenae 41(2): 7-28. (en catalán; in Catalan) ("The Epimagdalenian site of la Roureda Rockshelter (Vilafranca, els Ports, Valencian Country)”)

URL: http://www.raco.cat/index.php/Pyrenae/article/view/219642 
Román, D. 2011a, El poblament del final del Plistocè en les comarques del nord del País Valencià a partir de l'estudi tecno-tipològic de la indústria lítica. Tesi doctoral, Departament de Prehistòria i Arqueologia, Universitat de València, València, 628 p. (en catalán; in Catalan) ("The societies of the late Pleistocene in the northern Valencian Country from the techno-typological study of the lithic industry")

URL: http://www.tdx.cat/handle/10803/39089

Román, D. 2011b, La producción lítica en el abrigo de La Roureda (Vilafranca, Els Ports, Castellón). Saguntum-PLAV, 43: 21-31. (in Spanish) ("Lithic production at La Roureda rockshelter (Vilafranca, Els Ports, Castelló))” doi:10.7203/SAGVNTVM.43.331

Rey, M. 2013, Aproximación al estudio arqueopetrológico de la litoteca de la cuenca de la Charente (Francia), Tesis de Máster, Universidad de Barcelona, Barcelona, 161 p. (in Spanish) (“Archaeopetrological approach to the Charente's basin lithotheque”)

Riba, O. 1997, Diccionari de Geologia, Enciclopèdia Catalana, Institut d'Estudis Catalans, Barcelona, 407 p. (in Spanish) (“Geology Dictionary”) 


\title{
Archaeopetrological study of the lithic industry from "La Roureda” rockshelter (Vilafranca, Els Ports, Castellón, Valencian Country)
}

\author{
Mar Rey-Solé, Dídac Roman, Javier Mangado \\ SERP. Departamento de Prehistoria, Historia Antigua y Arqueología. Universidad de Barcelona. C/ Montalegre \\ 6. 08001. Barcelona, Catalonia. \\ Email: Rey-Solé: mreysole@ub.edu; Roman: didacroman@ub.edu; Mangado: mangado@ub.edu
}

\begin{abstract}
:
Roureda's (La Roureda) rockshelter is an Epimagdalenian site located in Vilafranca (northern Valencian Country) in the east of the Iberian Peninsula.

The site was discovered by Dr. F. Arasa in the late 1970s. More recently, two vertical trenches were dug at this site to determine the sequence of occupations over time: a $2 \mathrm{~m}^{2}$ trench on the rock shelter floor and a $1 \mathrm{~m}^{2}$ trench on the eroded area under the platform. The excavation of the $2 \mathrm{~m}^{2}$ in the rock shelter outlined an Early Epimagdalenian level dated to $11350 \pm 50 \mathrm{BP}(13373-13122 \mathrm{cal}$. BP).

One of the main features in this site is the abundant lithic industry recovered (4639 pieces), all of it made exclusively from chert. In recent years, the typology and technology of these materials has been studied but this is the first archaeopetrological study, not only for this site but for this region of Iberia.

Among the stone tools, backed bladelets are the most significant typological group, followed by the truncated bladelets and the group of notched-denticulates. End-scrapers and pieces with retouched edges are also important. The remaining groups represent less than $3 \%$.

The archaeopetrological study has been divided into two parts. Firstly, a macroscopic approach (petrographic and micropalaeontologic) was developed for all the retouched tools (286), the production blanks (2459) and cores (20). It should be note that during the excavations, 4639 elements were recovered, but about $45 \%$ of these being debris.

Secondly, geological surveys were developed, which allowed for the identification of several outcrops with cherts within a $100 \mathrm{~km}$ area around the site. Several samples of those cherts were microscopically compared to some of the archaeological lithic samples.

The results of these analyses allow for the identification of the presence of 4 different varieties of chert, with a primarily brackish or lacustrine origin. Two of them (Types A \& B) corresponding to a palustrine environment formation, one (Type $\mathrm{D}$ ) related to a marine environment formation, and finally, one (Type C) being undefined.

Two of these varieties, the most abundant in the site (Types A and B) may be related to several outcrops located both in a local and regional distance. Meanwhile, Types C and D are much less abundant.

The nearest varieties of chert to the site (Types A \& B), which are of high quality for knapping and relatively homogenous, were the most common in the Epimagdalenian level. These types showed all stages of the "Chaine Opératoire Lithique" (C.O.L.) within the site.
\end{abstract}


Nevertheless, a distinction can be observed between them. While Type A was used mainly for projectiles and in a lesser way for domestic tools, Type B was mainly used in the opposite way (mainly having been used for domestic tools). The explanation will likely be related to the homogeneity of their textural differences.

On the other hand, neither Type C nor Type D showed the complete sequence of the C.O.L. The first was probably introduced into the site mainly as knapped blades or bladelets, while Type D, the lowest in quality, was mainly used for domestic purposes. It was not possible to locate the outcrop of type C. Nevertheless, the outcrops of Type D are relatively abundant and in spite of its quality for knapping, this chert was frequently used. Outcrops of this type of chert can be found throughout the region.

The aim of this project in the near future is to enlarge this study to other Upper Palaeolithic and Mesolithic sites and develop a deeper knowledge of the siliceous outcrops used by hunter-gatherer populations in this region. This is a project of great relevance, not only for understanding the economy of raw materials at the Roureda rockshelter, but also for knowing the possibilities of chert trade in northern Valencian Country.

Keywords: flint; raw materials; archaeopetrology; Valencian Country; prehistoric mobility patterns 